\title{
O CURSO DE GEOGRAFIA FÍSICA DE IMMANUEL KANT (1724- 1804): UMA CONTRIBUIÇÃO PARA A HISTÓRIA E A EPISTEMOLOGIA DA CIÊNCIA GEOGRÁFICA
}

\author{
ALEXANDRE DOMINGUES RIBAS \\ Doutorando em Geografia \\ Universidade Estadual de Campinas \\ ANTONIO CARLOS VITTE \\ Professor do Departamento de Geografia \\ Universidade Estadual de Campinas
}

\section{As "idéias cosmológicas", o "Curso de Geografia Física" e seus respectivos lugares no itinerário da filosofia kantiana: três proposições primaciais}

Quedam em completa claudicação aqueles que imputam ao itinerário da filosofia kantiana uma uniformidade ou uma invariabilidade. Renunciando, em absoluto, a qualquer pretensão de pôr em dúvida a inflexível preocupação de Immanuel Kant com o caráter sistemático de sua filosofia (ou, então, de desconfiar da conformidade imanente a esta última), assentimo-nos assegurar que poucos nobres espíritos demonstraram - se confrontados com o filósofo de Königsberg - tamanha genialidade e intrepidez em reinventar-se a si mesmo, isto é, em revolucionar suas próprias idéias, alargando-as, re-significando-as e aprofundando-as. tomando como pujança a plasticidade, a amplidão e a fertilidade do âmago crítico que as abalizam.

Há, desse modo - perdoe-nos o provável uso impróprio do conceito ${ }^{1}$ - rugosidades (isto é, marcas amoldadas pela coexistência e/ou sucessão de ocasiões de continuidades-descontinuidades; interrupções-

Endereço eletrônico dos autores - Alexandre Ribas: ribasalex4@hotmail.com e Antonio Carlos Vitte: vitte@uol.com.br

1. Esse provável uso impróprio, de certo modo, não nos preocupa! Como assevera Schiller (1989), o entendimento, vezes sem conta, reduz o mundo a uma aparência fugaz e, para assim tratá-lo, tem que fixá-lo aos grilhões da regra, que descarnar seu belo corpo em conceitos e conservar seu espírito vivo numa precária carcaça verbal! 
ininterrupções; rupturas-manutenções-revoluções; saltos teóricos linearesrefluxo a fontes anteriores) no decurso de realização da filosofia kantiana. Por essa razão, incidiria em malogro a aspiração de encaixilhar o itinerário intelectual de Kant em uma taxonomia, pois que a complexidade de seu sistema crítico extrapola a toda e qualquer improfícua vontade classificatória ${ }^{2}$.

Atingimos, assim, a primeira "proposição primacial" dessa nossa exposição: a realização da filosofia kantiana manifesta-se, em seu itinerário, como um processo não-uniforme, não-invariável e, conseqüentemente, assinalado por rugosidades, apesar (ou, talvez, justamente por causa) de seu caráter sistemático.

Adentrando nos temas do sistema filosófico kantiano, encontramos junto a tantos outros desassossegos que afligiam essa mente impar - uma firme outorga de Kant às idéias de ordem propriamente cosmológica. Desse modo, a "problemática cosmológica" (ou seja, a questão em torno da metafísica do mundo) fez - assiduamente - companhia ao nosso filósofo no decurso da realização de sua empresa intelectual e, entre outras coisas, o governou a acossar o arranjo de um sistema cosmológico.

Essa pretensão em edificar um sistema cosmológico revela-se, pela primeira vez de forma sistematizada, em sua obra História Geral da Natureza e Teoria do Céu, publicada em $1755^{3}$. O interesse inicial de Kant pelas idéias cosmológicas parece ter sido despertado pelo largo e intenso debate filosófico que se içou em torno da metafísica do mundo (de modo especial, pela altercação - gerida, sobretudo por Leibniz e Wolff - diante do processo de laicização da investigação cosmológica e, por conseguinte,

2. Para validar tal idéia, salientamos, por exemplo, a relação filosófica de Kant com G. W. Leibniz (1646-1717). Não há dúvidas que Kant - por vezes, via Christian Wolff (16791754) - fez de Leibniz sua principal fonte inspiradora nos seus primeiros escritos (em sua denominada fase pré-crítica). O mesmo Leibniz parece - na Dissertação de 1770 e, sobretudo, na Crítica da Razão Pura (1781) e nos Princípios Metafísicos da Ciência da Natureza (1786) - lançado aos escombros quando da adesão de Kant a Isaac Newton (1642-1727) e à sua metodologia. Não obstante, eis que na Crítica da Faculdade do Juizo (1790), o velho Leibniz ressurge como fundamento - em Kant - para uma abordagem dinâmica da natureza em oposição à tese da imutabilidade da natureza de base newtoniana.

${ }^{3}$. Nessa obra, Kant se propõe, essencialmente, a descobrir “[...] o sistema (das Systematische) que reúne os grandes membros da criação em toda a extensão da infinidade" (KANT, 1984:65, tradução nossa) e a fazer derivar "[...] das leis mecânicas, a formação dos próprios corpos celestes e a origem de seus movimentos do primeiro estado da natureza [...]" (KANT, 1984:65, tradução nossa). 
do mecanicismo cartesiano e da filosofia natural de Newton) e, também, pela ocorrência, em 1755, do Terremoto de $\mathrm{Lisboa}^{4}$ (que fez fervilhar em solo europeu - a contenda a respeito da ordem e da finalidade da natureza).

Todavia, intrujam-se aqueles que abreviam o interesse de Kant pelas idéias cosmológicas ao seu escrito de $1755^{5}$. Na verdade, o motivo cosmológico persiste na extensão de todo o itinerário filosófico kantiano (CLAVIER, 1997). Para autenticar essa afirmativa basta grifarmos que já em 1747, em sua obra Pensamento sobre a verdadeira estimação das forças vivas ${ }^{6}$, Kant trata, mesmo que indiretamente, do objeto cosmológico. Em sua célebre Dissertação de 1770, nosso filósofo resignifica a problemática cosmológica, transmudando o sentido do conceito de mundo. Em 1781, sua sublime Crítica da Razão Pura praticamente desautoriza a razão cosmológica, sepultando-a ao lado das fantasiosas pretensões da metafísica clássica? . Contudo, o motivo cosmológico

${ }^{4}$. Esse episódio abalou, profundamente, a mentalidade européia da época. A conjectura do "melhor dos mundos possíveis", que exaltava o otimismo saído da filosofia de Leibniz, parecia ruir com a própria cidade de Lisboa e Voltaire - em seu Cândido ou o Otimismo ironicamente, proclamou sua falência. A natureza tem um fim? Ela possui uma ordem? Será o homem apenas o produto casual e temporário de uma natureza cega e sem propósito, tão-somente um espectador irrelevante de seus feitos, um intruso em seus domínios (BURTT, 1983)? Cabe algum lugar ao homem na teleologia cósmica? Indagações como estas viraram lugar-comum entre os pensadores europeus da época e Kant não escapou a elas! Além disso, esse acontecimento, entre outros aspectos, explica a adesão de Kant às lições de "Geografia Física", que ele passara a oferecer, em Königsberg, a partir de 1756.

${ }^{5}$ Estamos, obviamente, nos remetendo à obra História Geral da Natureza e Teoria do Céu.

${ }^{6}$ Nessa obra, segundo Clavier (1997), instigado pela questão "Que é preciso para fazer um mundo?" - questão esta, inclusive, que atravessa todo seu empreendimento intelectual - Kant constrói os conceitos de espaço, de lugar e de extensão, a partir da matéria e do movimento.

${ }^{7} \mathrm{Na}$ Crítica da Razão Pura, Kant afirma que abranger o mundo enquanto uma totalidade absoluta em si não passa de uma ambição nula da metafísica. Tal cobiça seria engravidada de uma contradição da razão especulativa consigo mesma, quando esta ousa exceder os limites da experiência. Se não podemos conhecer um objeto como coisa em si, mas apenas um objeto cuja intuição correspondente ao conceito pode nos ser dada, portanto, como fenômeno (objeto da intuição sensivel), logo, pretender apreender a alma, Deus e o mundo (como totalidade absoluta) é um ato sem préstimo, pois esses objetos não podem nos ser dados numa intuição. Essa contradição da razão consigo mesma, denunciada por Kant pelo mecanismo da Antinomia, neutraliza, consequentemente, 
ressurge e se revoluciona na Terceira Crítica de 1790, mediante a idéia de sistema, de organicismo da natureza, de juízo estético e de juízo teleológico ${ }^{8}$.

Assentimo-nos, assim, ostentar a segunda "proposição primacial" dessa nossa exposição: há uma declarada persistência do motivo cosmológico em toda a extensão da filosofia kantiana. E mais: o tratamento outorgado por Kant, em suas principais obras, às idéias cosmológicas esparge re-significações; variações; liames; continuidadesdescontinuidades; interrupções-ininterrupções; rupturas-permanências. E essa exasperada re-significação das idéias cosmológicas em Kant espelha, indiscutivelmente, a não-uniformidade e as rugosidades imanentes à sua filosofia.

As duas primeiras "proposições primaciais" até aqui oferecidas exprimem uma afinidade ingênita entre si: a) a filosofia kantiana (mesmo sendo sistemática) está longe de ser uniforme em seu decurso; ao contrário, ela manifesta-se em notórias rugosidades; b) o motivo cosmológico persiste em toda a extensão desta filosofia e, espelhando sua compleição, também se realiza de modo não-uniforme.

Há um verdadeiro deslocamento de sentido do conceito de mundo ao longo do decurso das idéias cosmológicas de Kant (CLAVIER, 1997). Esse continuado inclinar de Kant sobre o "conceito de mundo" e,

quaisquer produções cosmológicas. Desse modo, em sua Primeira Crítica, Kant declara "[...] fora de uso os conceitos metafísicos relativos ao mundo" (CLAVIER, 1997:7, tradução nossa) e, com isso, ele "[...] mandou os conceitos cosmológicos ao cemitério das hipóteses metafísicas" (CLAVIER, 1997:8, tradução nossa).

${ }^{8}$ Apesar de enviar, em sua Primeira Crítica, as produções cosmológicas ao cemitério das hipóteses metafisicas, Kant mantém uma abalizada persistência em seu projeto cosmológico. Clavier (1997), afirma que, já no Apêndice à dialética transcendental, Kant reconhece que a razão teórica pode encontrar um bom uso nas idéias cosmológicas, ao propor "[...] ao entendimento um fio diretor no exame da natureza" (p. 10, tradução nossa). A razão pode, com as idéias cosmológicas, detectar uma lei de unidade sistemática de todos os fenômenos. Portanto, Kant não abandona, em momento algum de seu itinerário filosófico, o interesse pela "unidade do todo do mundo". Tanto é que a força das Antinomias não abortou sua persistência pela "razão cosmológica" (CLAVIER, 1997). Isso se revela, por exemplo, em 1785, quando ele publica seu ensaio Sobre os vulcões da lua, onde conserva a hipótese cosmogônica da Teoria do Céu. E, em sua Terceira Crítica, Kant assume, claramente, que o "[...] idealismo transcendental interdita a cosmologia racional como parte da metafísica: mas ele não suprime a perspectiva cosmológica na investigação em Ciência da natureza" (CLAVIER, 1997:11, tradução nossa). 
conseqüentemente, sobre a possibilidade (ou não) de uma "metafísica do mundo", declara - incontestavelmente - o seu resoluto comprometimento com a construção metafísica da "superfície da Terra". Portanto, não foi por uma mera casualidade que Kant dedicou-se, tenazmente, à Geografia Física, ministrando-a, na forma de Curso, por quase quatro décadas na cidade de Königsberg. Assim como também não foi uma pueril eventualidade o fato de ele ter autorizado - no rematar de sua vida - a publicação de algumas notas deste seu Curso, em 1802.

Desse modo, mais do que um Curso ministrado para atender tãosomente a uma obrigação profissional ou financeira ou, então, para experimentar (e manifestar) seu gênio universal e enciclopédico, a "Geografia Física" - ininterruptamente - se mostrou, a Kant, como um conhecimento provido de uma desmedida significação metafísica, já que ela lhe sugeria a própria possibilidade de empiricização de sua filosofia. Conseqüentemente, seria um profundo desacerto desprender os estudos geográficos de Kant dos conteúdos e das intenções de seu sistema filosófico.

Encontramo-nos, então, ante a terceira "proposição primacial" que esteia essa nossa exposição: a "Geografia Física" (curso professorado por Kant durante quase quatro décadas e que, em 1802, foi editado por Th. Rink na forma de livro) espelha (no sentido de ser um produto) as resignificações experimentadas pelas idéias cosmológicas no trajeto da realização da filosofia transcendental kantiana. Ao mesmo tempo, a Geografia Física, atua como uma espécie de força geratriz destas resignificações sofridas pela cosmologia kantiana quando denuncia, aos olhos do filósofo de Königsberg, a empiricidade (e a heterogeneidade) do mundo e o obriga a formular uma nova imagem de natureza. Essa nova imagem - que suplanta a submissão da natureza à simetria totalizante da Razão e à redimensiona mediante a aplicação do juízo reflexivo como componente de sua apreensão e de sua representação - aparece nas páginas de sua sublime Crítica da Faculdade do Juízo, publicada em 1790.

Eis, de tal modo, as três "proposições primaciais" enlaçadas ternamente: a) não devemos sucumbir ao equívoco de conferir à filosofia kantiana um itinerário uniforme. Essa altiva filosofia - apesar de seu inabalável desejo de sistema e da conformidade a ela pertencente realiza-se, em seu transcurso, mediante rugosidades; b) do mesmo modo, não podemos cair na claudicação de abreviar a "problemática" cosmológica kantiana ao seu escrito de 1755. O motivo cosmológico persiste na extensão de todo empreendimento intelectual de Kant. Por se mostrar pertinaz ao longo de toda a superficie da filosofia kantiana, esse 
motivo cosmológico acaba por espelhar as rugosidades ingênitas a esta filosofia; c) o Curso de Geografia Física - ministrado por Kant por quase quarenta anos - não pode ser dissociado do conteúdo e do alcance das duas proposições anteriores. $O$ interesse de Kant pela Geografia sempre foi eminentemente metafísico, filosófico. Ela, a Geografia Física, é tanto um produto como, também, uma peça impulsionadora dessa nãouniformidade imanente à filosofia e ao motivo cosmológico kantianos. A Geografia Física instiga nosso filósofo a redimensionar seu conceito de mundo e a buscar apreender a multiplicidade da natureza para além da simetria totalizante da Razão. A Geografia Física, por fim, compõe a "experiência estética" que sustenta a nova imagem de natureza aclamada por Kant em sua Crítica da Faculdade do Juízo, datada de 1790.

\section{A “Geografia Física” de Kant: notas sobre sua transmutação de Curso em Livro}

$\mathrm{O}$ que teria levado Kant - considerado, por muitos, como sendo o modelo ímpar do filósofo ${ }^{9}$ - a auferir autoridade à Geografia Física, a ponto de oferecer um Curso dirigido a esta disciplina? Já asseguramos, anteriormente, que desprender os estudos geográficos de Kant de suas intenções filosóficas não passa de um ato sem préstimo. $\mathrm{O}$ interesse de Kant pela Geografia Física jamais esteve cingido a uma mera atividade professoral ou a um simples hábito enciclopédico; ao contrário, ele sempre foi fundamentalmente filosófico, compondo seu intento metafísico e cosmológico.

Kant ofereceu Cursos de Geografia Física por quase quarenta anos, em Königsberg. Todavia, ele jamais escreveu uma obra designadamente direcionada a esta disciplina. Na verdade, Kant elaborava alguns manuais que eram empregados nas suas aulas de Geografia Física. Ele era assíduo leitor de narrativas de viagens, de relatos de expedições científicas, de jornais, revistas, etc. Ou seja, Kant - inegavelmente - possuía um cabedal expressivo de informações geográficas (geodésicas, corográficas, etc.) sobre diversos países. Algumas notas destes manuais elaborados por Kant foram publicadas, em 1802, por um de seus antigos alunos, Thomas Rink. Possivelmente, tais notas - que foram encontradas em dois cadernos exprimem conteúdos e concepções expostas por Kant, em seu Curso, já na fase mais derradeira de sua vida.

9. De Quincey (1989), por exemplo, assevera não existir um único escritor filosófico que possa pretender aproximar-se de Kant na extensão ou na profundidade da influência exercida sobre as mentes dos homens. 
Aquilatamos ser proeminente (e, ao mesmo tempo, indispensável) ostentar uma exposição mais meticulosa desse processo de transmudação da Geografia Física de Kant de Curso em Livro, principalmente para podermos situá-la no bojo da dilatada e infatigável atividade professoral deste eminente e egrégio filósofo.

No outono de 1740, no dia de São Miguel, após freqüentar por oito anos o Collegium Fridericianum, Kant foi conduzido à Universidade de Königsberg, onde seguiu os cursos de filosofia, que abarcavam a filosofia propriamente dita e as ciências (PASCAL, 1996; DE QUINCEY, 1989).

Em 1747, com o falecimento de seu pai, Kant vê-se obrigado a abandonar a Universidade, antes mesmo de ter adquirido todos os seus graus acadêmicos. A partir de então, para ganhar a vida, ele passa a desempenhar a função de preceptor de famílias ricas tanto de Königsberg como de seus arrabaldes. Ele exerceu o cargo de preceptor por, aproximadamente, nove anos (PASCAL, 1996).

Kant, próximo dos seus 30 anos, já havia se decidido pelo trabalho na Universidade. Seguindo a tal ambição, em 12 de junho de 1755 ele obteve o apetecido título de licenciado junto à Faculdade de Filosofia de Königsberg e, desde então, passou a estar habilitado a abrir um curso livre (BOROWSKI, 1993).

Impetrada a habilitação para oferecer cursos livres, Kant encetou suas lições de Lógica (seguindo a Meier), de Metafísica (seguindo, primeiramente, a Baumeister e, posteriormente, a Baumgarten), de Física (seguindo a Eberhard) e de Matemática (seguindo a Wolff) (BOROWSKI, 1993). Em seguida, pôs-se a instruir conferências sobre Direito Natural, sobre Moral, sobre Teologia Natural e, mais tarde, sobre Antropologia e sobre Geografia Física (BOROWSKI, 1993).

Kant desempenhou a função de Docente Livre por quatorze anos, sendo seus cursos financiados pelos próprios alunos (PASCAL, 1996). Kant tentou elevar-se ao cargo de catedrático em 1756 e ainda em 1758, mas não auferiu êxito. Em 1767, foi-lhe oferecida a cátedra de Poética, mas ele prontamente recusou. Aceitou, no entanto, em 1767, o posto de inspetor na Biblioteca Real, mas abdicou do mesmo em 1772, em razão da amplidão de suas outras atividades, que o impedia de dedicar-se com inteireza à referida função (BOROWSKI, 1993).

Em 1770, com sua célebre Dissertação sobre a forma e os princípios do mundo sensivel e do mundo inteligível, Kant foi designado para a cátedra de matemática, que pouco depois ele permutaria pela de lógica e 
metafísica. Com isso, ele conseguira, finalmente, o posto de professor titular ou ordinário.

Mesmo após ter se estabelecido como docente titular da Universidade de Königsberg, Kant prosseguiu exercendo o ofício de professor por conta própria (isto é, de maneira autônoma) até 1793 . Na verdade, para sermos mais exatos, ele manteve suas lições públicas até, aproximadamente, o ano de 1797. Aos seus cursos privados, Kant renunciou em 1793, porque suas forças já estavam escassas para oferecêlos com probidade. Aos que procuravam por seus cursos, a partir desta data, Kant indicava os professores Pörschke, Gensichen e o licenciado Jesche (BOROWSKI, 1993).

Desse modo, até o interromper de sua vitalidade, ou seja, até o definhar de sua eficácia, Kant continuou, ininterruptamente, a ministrar seus cursos. E, para o sobressalto de muitos, não era filosofia que ele ensinava primordialmente. Kant ofertou - ao longo de sua atividade acadêmica (estreada em 1755/56 e rematada em 1796/97) aproximadamente, 267 ciclos de cursos, sendo que, destes, 54 foram dedicados à lógica e à metafísica $(20,2 \%) ; 49$ à geografia física $(18,4 \%)$; 46 à ética $(17,2 \%) ; 28$ à antropologia (10,5\%); 24 à física teórica $(8,9 \%)$; 20 às matemáticas $(7,5 \%) ; 16$ ao direito $(6 \%) ; 12$ à enciclopédia das ciências filosóficas $(4,5 \%) ; 11$ à pedagogia $(4,1 \%) ; 4$ à mecânica $(1,6 \%) ; 2$ à mineralogia $(0,7 \%)$ e 1 à teologia $(0,4 \%)$.

Notamos que a Geografia Física foi, ao longo da atividade acadêmica de Kant, a segunda disciplina mais lecionada, exatamente depois da lógica e da metafísica. Isentando a inegável e irrefragável importância quantitativa desta ciência no total dos cursos por ele administrados, Kant foi, ainda, "[...] o primeiro filósofo a introduzir esta disciplina à Universidade antes mesmo que a primeira cadeira de Geografia fosse criada por Karl Ritter, em Berlim, em 1820" (COHENHALIMI, 1999:11, tradução nossa).

Isso não significa, em hipótese alguma, que antes de Kant esta disciplina não fosse ensinada em território europeu. No entanto, nenhum filósofo havia se interessado pela geografia como Kant "[...] a ponto de ensinar e de redigir um manual a este fim" (COHEN-HALIMI, 1999:11, tradução nossa).

Não havia, de fato, nenhum manual que pudesse servir-lhe como referência e: 
[...] por isso ele redigiu a Geografia Física, e este fato é tanto mais notável que na época, ele era estritamente proibido de professar um curso em seu próprio nome, cada professor devia se conformar a um manual oficialmente reconhecido. A exceção da Geografia Física fez assim o objeto de um decreto de von Zedlitz, de 16 de outubro de 1778, pelo qual Kant era autorizado a ensinar esta disciplina segundo suas notas, conforme as suas notas ou ainda segundo as suas próprias notas (COHEN-HALIMI, 1999:11, tradução nossa).

Esse manuscrito, elaborado por Kant e empregado como referência às suas aulas de Geografia Física, acrescido por notas tomadas por seus estudantes durante os cursos, apareceu só tardiamente, em 1802, sendo que sua edição fícou sob o encargo de Thomas Rink, um antigo aluno especialmente selecionado por Kant para a publicação do que viria a se tornar um livro.

O caráter tardio de sua publicação permite-nos entender a razão que leva Cohen-Halimi (1999) a concluir que "[...] de fato, o Curso de Geografia Física acompanha por assim dizer clandestinamente todo o percurso filosófico de Kant [...]" (p. 10, tradução nossa). Destarte, apesar deste mistifório entre o manuscrito de Kant e as notas adicionadas por seus alunos-ouvintes, algumas pesquisas filológicas (como a de E. Adickes) "[...] permitem ter o Curso de Geografia como uma obra kantiana autêntica [...]" (COHEN-HALIMI, 1999:9, tradução nossa). Isso porque seu conteúdo espelha um curso concebido e professorado por Kant e, por mais que esta seja uma obra reconstituída a partir do acréscimo de notas tomadas por estudantes, ela é considerada como parte integrante da herança intelectual kantiana.

\section{A Geografia e a Geografia Física em Kant: apontamentos conceituais}

O livro Geografia Física ${ }^{10}$ é iniciado com uma Introdução à Descrição física da Terra. Trata-se, este, de um momento em que Kant entre outros assuntos - prende sua atenção em exibir uma definição de geografia (fisica).

Kant, primeiramente, define a geografia (física) como sendo uma propedêutica do conhecimento do mundo. E o mundo, para ele, significa a totalidade (o solo sobre o qual nossos conhecimentos são adquiridos e

\footnotetext{
${ }^{10}$ Essa obra se encontra no tomo IX da edição das obras de Kant realizada pela Academia de Ciências da Prússia (1902), Berlim, Walter de Gruyter, 1968 (KANT, 1999).
} 
aplicados) que, por sua vez, é a condição sine qua non para a representação do homem e da natureza enquanto um sistema.

$\mathrm{O}$ desejo de sistema submete, para Kant, os estudos geográficos. Desse modo, em sua acepção, o escopo arquitetônico subjuga o conhecimento do mundo. É essa pretensão arquitetônica (sistêmica) que funda esta ciência, fazendo-a tratar o múltiplo como sendo derivado do todo. É por essa razão que ele define a geografia (física) como sendo uma descrição da Terra inteira, ou, o conhecimento do mundo (KANT, 1999).

É importante grifar que, para Kant, a geografia (física) seria a única ciência apta a descrever a superfície da Terra em sua totalidade, isto é, a descrever e representar a natureza enquanto um sistema. Desse modo, Kant afirma ser a geografia (física) uma descrição raciocinada de tudo o que é visível à superficie terrestre. Para ele, portanto, a geografia (física) não seria uma mera descrição, mas uma descrição associada "[...] às causas imediatas dos efeitos da superfície que ela descreve" (MARCUZZI, 1999:45, tradução nossa). Por isso, a geografia (física) seria um inventário raciocinado dos quadros do mundo, ou então, uma descrição raciocinada da superfície da Terra.

Kant também se preocupa, nesse cometimento conceitual, em "[...] designar a todos os conhecimentos o lugar que lhe é próprio" (1999:68, tradução nossa). E, no que tange ao ordenamento dos conhecimentos empíricos, estes só podem ser alocados seja sob conceitos, seja segundo o tempo e o espaço onde os encontramos realmente (KANT, 1999). A divisão dos conhecimentos segundo conceitos, Kant denomina de divisão (classificação) lógica; já a divisão que é feita segundo o tempo e o espaço, ele designa de divisão (classificação) física. Pela primeira, diz ele, "[...] obtemos um sistema da natureza [...] como por exemplo [...] o de Linneu, pela segunda [...] uma descrição geográfica da natureza" (KANT, 1999:67 e 68 , tradução nossa).

A classificação física (que se opõe à classificação lógica) se demonstraria - para Kant - segundo o tempo (história) e segundo o espaço (geografia). Dessa maneira, tanto a história como a geografia seriam conhecimentos históricos; porém, a primeira seria uma narração e a segunda uma descrição (KANT, 1999). Nesses termos, a geografia buscaria, portanto, descrever o lugar das coisas sobre a superfície da Terra, propondo uma divisão física dos fenômenos distribuídos sobre a Terra e não uma divisão lógica no sentido de Linneu (que pretendia, essencialmente, classificar as coisas mediante suas semelhanças ou dessemelhanças). A descrição geográfica, deste modo, espelharia o teatro 
da natureza, a "[...] Terra em si mesma e as regiões onde se acham realmente as coisas [...]” (1999:69, tradução nossa).

Contudo, surge, nesse momento, uma indagação relevante: qual o atributo que não comparece na classificação lógica e que, ao mesmo tempo, concede especificidade à classificação física? Diz o filósofo de Königsberg: é o espaço que é negligenciado na classificação lógica e é este atributo que fornece a especificidade (e a fertilidade) da classificação física. Desse modo, para Kant, o espaço outorga à classificação física o atributo de fazer ver os conteúdos da empiricidade do mundo e da natureza.

É justamente essa espacialidade da superfície da Terra, ou seja, essa empiricidade distribuída (e ordenada) espacialmente, que uma mera divisão conceitual não consegue alcançar e representar. Essa qualidade atinente à classificação física nos aclara, assim acreditamos, as razões que encaminharam Kant à geografia. Esta disciplina lhe concedia a possibilidade de representar o mundo como um sistema, ou então, de representar a natureza teleologicamente organizada.

Após desunir a geografia das classificações lógicas (distinguindo a divisão lógica da divisão física), Kant busca discriminá-la da história (demonstrando a diferença entre uma divisão física segundo o tempo e uma divisão física segundo o espaço). E o elemento discriminante primordial, mais uma vez, é o espaço; é ele que especifica o estudo geográfico face ao exame histórico. Seguindo a esta acepção, Kant assevera que "[...] a história como a geografia podem ser chamadas todas duas uma descrição, com esta diferença [...] que a primeira é uma descrição segundo o tempo e a segunda uma descrição segundo o espaço [...]" (1999:69, tradução nossa).

Nesse âmbito, para Kant, tanto a história como a geografia "[...] alargam pois o campo de nossos conhecimentos do ponto de vista do tempo e do espaço" (1999:69, tradução nossa). Entretanto, a história "[...] diz respeito aos eventos que são desenrolados uns após os outros do ponto de vista do tempo [...]" (KANT, 1999:69, tradução nossa), ao passo que a geografia "[...] diz respeito aos fenômenos que se produzem ao mesmo tempo do ponto de vista do espaço [...]” (p. 70, tradução nossa). Todavia, de acordo com os objetos que ela trata, a geografia, na concepção de Kant, toma diferentes nomes: geografia física, geografia matemática, geografia política, geografia moral, geografia teológica, geografia literária ou geografia de mercado. 
Apoiando-se em tais assertivas, Kant chega à sua ilação principal: “[...] A história é uma narrativa enquanto que a geografia é uma descrição. Por conseguinte, nós podemos bem ter uma descrição da natureza mas não uma história da natureza" (Kant, 1999:70, tradução nossa). E nosso filósofo emenda: “A geografia e a história preenchem a totalidade (IX, 163) do campo de nossos conhecimentos: a geografia, o do espaço, e a história, o do tempo" (KANT, 1999:72, tradução nossa).

Eis, então, a geografia desprendida da história e, conseqüentemente, da história natural, sobretudo, da de Buffon. E o responsável por esta emancipação, é o espaço, que permitiu a separação da geografia dos sistemas lógicos, como o de Linneu, que visava a classificação da natureza, segundo uma ordem fundamentada na teologia natural. O próprio Kant assevera que: "É pois somente do ponto de vista do espaço e do tempo que a história (Historie) difere da geografia" (1999:70, tradução nossa).

Essa descoberta da natureza na superfície da Terra, exige uma nova lógica, uma nova linguagem, novos símbolos e, enfim, uma nova metáfora para a natureza e seus processos. Há uma des-teleoligização da natureza pelos estudos científicos. Esse é o momento em que ocorre a emancipação da geografia física moderna. Segundo Büttner (1975):

Kant joints the debate by making clear with inexorable poingnancy (in doing so he goes decisively further than his teacher Wolff) that geography can help neither to prove the existence of God nor furnish proof against his existence (as the advocates of the French Enlightenment especially tried to do). Geography is theologically neutral (BUTTNER, 1975:239).

Nesse sentido, para Kant, a geografia apresentava-se como uma ciência dotada de uma fecundidade única pois, por ser discriminada da divisão lógica, ela se revelava em condições de representar a empiricidade real da superfície da Terra (ou os quadros do mundo); ao passo que, por ser desunida da história natural de Buffon, essa ciência mostrava-se capaz de espelhar a sistematicidade da natureza organizada (ou seja, sua teleologia). E é encostado nessas considerações que Kant se sente à vontade para lançar sua concepção mais límpida (e exata) de geografia: ela é uma descrição segundo o espaço (KANT, 1999).

\section{"Geografia Física", Cosmologia e Estética em Kant: considerações finais}


Incontestavelmente, o que concebemos por geografia moderna (e, logo, científica) é um corpo de saberes resultante de problemas filosóficos. Essa assertiva - aparentemente tão prosaica - pode conduzir-nos a conseqüências deveras ressaltantes, caso nos coloquemos a perscrutar a gênese epistemológica da ciência geográfica.

A história da ciência geográfica, vezes sem conta, é-nos narrada como uma sucessão unidimensional de biografias de algumas ilustres personalidades. Se nos perdermos - ocasionalmente - nestes sedutores fragmentos biográficos, acabamos por deslembrarmos que a geografia moderna (e científica) insurge em meio a um projeto de explicação do mundo. Ou seja, ela nasce de um pacto para se explicar e construir o mundo.

E, dentro deste pacto, a geografia concede à Modernidade um projeto de construção da "superfície da Terra", isto é, ela empiriciza a invenção do mundo, via invenção do que é a "superfície da Terra". Logo, permitindo essa construção metafisicica da "superfície da Terra", ou seja, concedendo um atributo científico à validação do empírico da Modernidade, a geografia moderna (e cientifica) declara-se como uma derivação direta de problemas eminentemente filosóficos, ou, então, como produto de um projeto da Razão humana.

Nessa peregrinação da geografia pela Modernidade, Bernhard Varenius (1621-1650) exercera a tarefa de tentar formatar, numa linguagem geográfica, a física de René Descartes (1596-1650). Kant - que foi um leitor atento dos escritos de Varenius - parece entregar-se a um procedimento similar; entretanto, ao invés da física cartesiana, ele busca geografizar a física de Isaac Newton (1642-1727). Newton, aliás, foi quem oficializou a noção de espaço, fazendo de seu caráter absoluto o sustentáculo da imutabilidade da natureza, mediante sua lei da inércia (NEWTON, 2008).

Newton foi, inegavelmente, um modelo a Kant durante boa parte de sua laboração intelectual. Sua Crítica da Razão Pura (1781), por exemplo, exala newtonianismo, ao fazer da metodologia empregada pelo filósofo inglês um verdadeiro cânone da Razão. Kant chega, por vezes, a ser mais newtoniano que o próprio Newton!

Não por acaso, julgando a pertinência das críticas dirigidas por Leibniz (via Clarke) a Newton - acusando o newtonianismo de não possuir uma fundamentação metafisica - Kant escreveu seus Princípios Metafísicos da Ciência da Natureza em 1786 (KANT, 1990) justamente para balizar, filosófica e metafisicamente a física de Newton. 
Mais do que nunca, Kant, nessa sublime obra, assume o newtonianismo como uma metodologia e, com sua sagacidade impar, praticamente autoriza a existência de uma "ciência da natureza". A Crítica da Razão Pura (KANT, 1982) e os Princípios Metafísicos da Ciência da Natureza (KANT, 1990) são essencialmente newtonianos, estando estritamente sustentados na matemática e na geometria de Newton.

Kant, assim, chega em meados de 1780 com um aporte newtoniano sólido e inabalável. Sua concepção de espaço, em linhas gerais, alinhavase com o espaço absoluto newtoniano. Kant apenas transfere o resguardo de sua universalidade num a priori da sensibilidade. Sua idéia de natureza escorava-se na tese da imutabilidade da natureza de base newtoniana, cimentada pela lei da inércia. A natureza, assim concebida, ficava num estado de subserviência ao universalismo do entendimento.

Chegamos a um ponto em que tudo parecia resolvido a Kant! Pois, segundo o próprio filósofo de Königsberg, a "reflexão racional" se exerce em dois domínios: o teórico e o prático-moral. Em suas duas primeiras Críticas, Kant havia lançado - de modo bastante radical - novos fundamentos da experiência, quer de um ponto de vista estritamente teórico, quer do ponto de vista da teoria moral. Definindo os limites em que o saber teórico ou o prático podem e devem se desenvolver, o programa crítico kantiano parecia ter chegado ao fim (MARQUES, 1998).

Eis, então, que o velho Kant, já no anoitecer de sua vida, ousa revolucionar sua própria filosofia e decide publicar sua Crítica da Faculdade do Juízo, no ano de 1790 (KANT, 1985). Não teriam, já, as Críticas precedentes tratado do uso prático e teórico da razão? Por que, então, uma Terceira Crítica? O que teria ficado em aberto em suas outras Críticas?

Kant formulou a Terceira Crítica em razão de algumas lacunas por ele sentidas. Lacunas estas não simplesmente deixadas por alguma incompletude imanente às Críticas anteriores, mas ingênitas à completude (e às necessidades) de um sistema do qual elas faziam parte. E quem despertou nosso sublime filósofo para o reconhecimento de tais lacunas foi a "natureza" (MARQUES, 1998).

Essa re-significação - derramada na Terceira Crítica - coincide com o momento em que Kant passa a questionar o paradigma geométricomatemático newtoniano. $\mathrm{O}$ próprio Kant reconhece que, na Crítica $d a$ Razão Pura, ele abordou a "natureza" tão-somente a partir do que o entendimento prescrevia a priori como lei para ela, isto é, enquanto um complexo de fenômenos (cuja forma é dada igualmente a priori). A 
"natureza" parecia esvaída frente a esse poder simétrico da Razão todopoderosa!

Dessa maneira, como já asseveramos antes, as noções de espaço e de natureza, defendidas por Kant até 1790, espelhavam a tese da imutabilidade da natureza, austeramente amparada na lei da inércia de Newton. Mas como esse espaço a priori (universal) e essa natureza (imutável) poderiam se enlaçar com o empírico, com a multiplicidade fenomênica? Se a natureza é universal, por que ela se manifesta enquanto multiplicidade? Como pode ser diferente o que é universal?

A Crítica da Faculdade do Juízo (KANT, 1995) busca responder a tais indagações. E, para levar a efeito tal empresa, o velho Kant vai regressar a Leibniz e à sua concepção dinâmica de natureza. Ele vai retomar, do mesmo Leibniz, a idéia de espaço como "coexistência entre seres/entes", rompendo com sua universalidade e necessidade apriorística. Do mesmo modo, ele regressa a Platão e retoma deste o conceito de forma. Como resultado dessa revolução, ele formula a noção de juízo.

E a noção de juízo vem justamente tentar aproximar os domínios da natureza e da liberdade; e isso leva - em Kant - a um interesse renovado pela própria natureza. Desse modo, na Crítica do Juízo, Kant busca restaurar a imagem da natureza resultante da Crítica da Razão Pura. Sua Terceira Crítica vem, precisamente, exibir um novo modelo de inteligibilidade da natureza.

Essa nova imagem de "natureza" é fabricada em meio às preocupações de Kant em redefinir a própria relação entre o particular e o universal. Para apreender a particularidade do particular e para produzir uma representação da "natureza" em sua materialidade fenomênica, Kant lança mão das noções de conformidade a fins, juízo reflexivo, juízo estético e juízo teleológico. Eis uma sensível fenda aberta em direção à representação da plasticidade da "natureza".

A noção de conformidade-a-fins vai exercer forte influência em J.W. Goethe (1749-1832), sobretudo em sua noção de morfologia; e em Alexander von Humboldt (1769-1859), especialmente em sua idéia de conexão entre os diferentes elementos da natureza. Kant, portanto, é indiscutivelmente - uma fonte de onde deságuam os pilares para a edificação epistemológica da geografia em sua conotação moderna (VITTE,2008; SILVEIRA, 2008).

Kant, nas páginas de sua Crítica do Juízo, concede o primeiro passo em direção à possibilidade de encontrar o universal no singular mediante a "experiência estética". Kant, na verdade, inventa a estética moderna! 
Schiller (1759-1805) - que produz uma verdadeira reconstrução da filosofia kantiana - leva ao extremo o uso da "experiência estética", especialmente com sua noção de "impulso lúdico". Goethe, nos vôos de sua genialidade, concebe a ciência como um modo de experenciar o belo. Humboldt - amigo de Schiller e de Goethe - escreve seus "Quadros da Natureza" (HUMBOLDT, 1953) justamente como tentativa de fazer ciência como uma "experiência estética". Entretanto, ele vai além e funda a representação da espacialidade da natureza.

Nesse cenário aqui singelamente desenhado, resta-nos uma última indagação: o que teria despertado Kant para a heterogeneidade e a empiricidade da "natureza"? O que teria chamado sua atenção para as formas diversas da natureza, para suas particularidades e para suas conformidades a fins? O que o teria empurrado a formular um novo modelo de inteligibilidade da "natureza"?

Longe de se apegar a uma única causa para esse despertar, ou, então, para essa verdadeira revolução operada por Kant no findar de seu empreendimento filosófico, não hesitamos em afiançar que seu "Curso de Geografia Física" serviu como uma das forças geratrizes para tão profícua e sublime reinvenção!

\section{O CURSO DE GEOGRAFIA FÍSICA DE IMMANUEL KANT (1724-} 1804): UMA CONTRIBUIÇÃO PARA A HISTÓRIA E A EPISTEMOLOGIA DA CIÊNCIA GEOGRÁFICA

Resumo: Há um relativo depauperamento no tocante ao nosso conhecimento a respeito da relação entre a filosofia kantiana e a constituição da geografia moderna e, conseqüentemente, científica. Esta relação, quando abordada, o é - vezes sem conta - de modo oblíquo ou tangencial, isto é, ela resta quase que exclusivamente confinada ao ato de noticiar que Kant ofereceu, por aproximadamente quatro décadas, cursos de Geografia Física em Königsberg, ou que ele foi o primeiro filósofo a inserir esta disciplina na Universidade, antes mesmo da criação da cátedra de Geografia em Berlim, em 1820, por Karl Ritter. Não ultrapassar a pueril divulgação deste ato em si mesma só nos faz jogar uma cortina sobre a ausência de um discernimento maior acerca do tributo de Kant à fundamentação epistêmica da geografia moderna e científica. Abrir uma frincha nesta cortina denota, necessariamente, elucidar o papel e o lugar do "Curso de Geografia Física" no corpus da filosofia transcendental kantiana. Assim sendo, partimos da conjectura de que a "Geografia Física" continuamente se mostrou, a Kant, como um conhecimento portador de um 
desmedido sentido filosófico, já que ela lhe denotava a própria possibilidade de empiricização de sua filosofia. Logo, a Geografia Física seria, para Kant, o embasamento empirico de suas reflexões filosóficas, pois ela the comunicava a empiricidade da invenção do mundo; ela the outorgava a construção metafisica da "superfície da Terra". Destarte, da mesma maneira que a Geografia, em sua superficie geral, conferiu uma espécie de atributo científico à validação do empírico da Modernidade (desde os idos do século XVI), a Geografia Física apresentou-se como o sustentáculo empírico da reflexão filosófica kantiana acerca da "metafísica da natureza" e da "metafísica do mundo".

Palavras-chave: História e Epistemologia da Geografia, Geografia Física, Cosmologia, Filosofia Transcendental Kantiana, Natureza.

\section{THE COURSE OF PHYSICAL GEOGRAPHY OF IMMANUEL KANT (1724-1804) : CONTRIBUTION FOR THE GEOGRAPHICAL SCIENCE HISTORY AND EPISTEMOLOGY}

Abstract: There is a relative weakness about our knowledge concerning Kant philosophy and the constitution of modern geography and, consequently, scientific geography. That relation, whenever studied, happens - several times - in an oblique or tangential way, what means that it lies almost exclusively confined in the act of notifying that Kant offered, for approximately four decades, "Physical Geography" courses in Konigsberg, or that he was the first philosopher teaching the subject at any College, even before the creation of Geography chair in Berlin, in 1820, by Karl Ritter. Not overcoming the early spread of that act itself only made us throw a curtain over the absence of a major understanding about Kant's tribute to epistemic justification of modern and scientific geography. To open a breach in this curtain indicates, necessarily, to lighten the role and place of Physical Geography Course inside Kantian transcendental philosophy. So, we began from the conjecture that Physical Geography has always shown, by Kant, as a knowledge carrier of an unmeasured philosophic sense, once it showed the possibility of empiricization of his philosophy. Therefore, a Physical Geography would be, for Kant, the empirics basis of his philosophic thoughts, because it communicates the empiria of the world invention; it has made him to build metaphysically the "Earth's surface". In the same way, Geography, in its general surface, has given a particular tribute to the empiric validation of Modernity (since the $16^{\text {th }}$ century), Physical Geography introduced itself as an empiric basis to Kantian philosophical reflection about "nature's metaphysics" and the "world metaphysics" as well. 
Keywords: History and Epistemology of Geography, Physical Geography, Cosmology, Kantian Transcendental Philosophy, Nature.

\section{BIBLIOGRAFIA}

BOROWSKI, Ludwig Ernst. 1993. Relato de la vida y el carácter de Immanuel Kant. Madri: Tecnos.

BURTT, Edwin Arthur. 1983. As bases metafísicas da ciência moderna. Brasília: Editora Universidade de Brasília.

CLAVIER, Paul. Kant. 1997. Les idées cosmologiques. Paris: Presses Universitaires de France.

COHEN-HALIMI, Michèle. 1999. Le Géographe de Königsberg. In: KANT, Immanuel. Géographie. Physische Geographie. Paris: Aubier, p. 9-40.

HUMBOLDT, Alexander von. 1953. Quadros da Natureza. SP: W.M. Jackson Inc., 2 vols.

DE QUINCEY, Thomas. 1989. Os últimos dias de Immanuel Kant. Rio de Janeiro: Forense Universitária.

KANT, Immanuel. 1982. Crítica da Razão Pura. Lisboa: Fundação Gulbenkian.

. 1990. Primeiros Princípios Metafísica da Ciência da Natureza. Lisboa: Edições 70.

. 1995. Crítica da Faculdade de Julgar. Rio de Janeiro: Forense Universitária.

. 1999. Géographie. Physische Geographie. Paris: Aubier.

. 1984. Histoire Générale de la Nature et Théorie du Ciel. Paris:

Librairie Philosophique J. Vrin.

MARCUZZI, Max. 1999. La "Géographie Kantienne": délimitation de la discipline. In: KANT, Immanuel. Géographie. Physische Geographie. Paris: Aubier.

MARQUES, Antonio. 1998. A Terceira Crítica como culminação da filosofia transcendental kantiana. In: KANT, Immanuel. Crítica da Faculdade do Juizo. Lisboa: Imprensa Nacional - Casa da Moeda.

PASCAL, Georges.1996. O pensamento de Kant. Petrópolis: Editora Vozes.

SCHILLER, Friedrich. 1989. A educação estética do homem. Numa série de cartas. São Paulo: Iluminuras. 
SILVEIRA, Roberison W. D. da. 2008. As influências da filosofia kantiana e do movimento romântico na gênese da geografia moderna: os conceitos de espaço, natureza e morfologia em Alexander von Humboldt. Campinas: Instituto de Geociências, Dissertação de Mestrado (Geografia), 2008.

VITTE, Antonio C. 2008 . A geografia física: da conformidade-a-fins à paisagem. Caderno Prudentino de Geografia, n. 30. Presidente Prudente (prelo). 